\title{
DEMAND ESTIMATION FOR A NEW AIR ROUTE
}

Jong Hae Choi ${ }^{1}$

Senior Manager, Corporate Innovation Team Incheon International Airport Corporation, Korea

Yong Wha Park ${ }^{2}$

Dean, Asia Pacific School of Logistics, Inha University, Korea

Sang-Yong Lee $^{3}$

Director, Coporate Strategy \& Planning Team Incheon International Airport Corporation, Korea

Kwang Soo Lee Le $^{4}$

Vice President, Passenger Service Division, Incheon International Airport Corporation, Korea

\section{ABSTRACT}

Network connectivity is core competitiveness of the aviation industry and opening a new route is one of critical ways to enhance network competitiveness. As many airport operators are becoming more interested in attracting airlines, there are vast needs to discuss the methods for estimating (predicting) potential demands for a new flight route or by increasing flight frequencies in existing routes.

This study explores demand estimation models for a new air route. Similar to previous studies, this study classified potential demand for a new air route into four types (Local, Beyond, Behind and Bridge). Explanatory variables are identified and constructed for each type of demand, including distance, relative capacity compared with adjacent airports and detour ratio as main independent variables. One of the strengths of the suggested demand models can distinguish the generated demand from the converted or re-distributed demand. Based on this, the model is meaningful for an airport operator to develop an airport policy such as airport-usage charges and incentives to attract airlines.

On the other hand, because of the strong recognition that demand estimation for a new air route is the area of airlines that decide on whether or not to introduce a new route, simply developing demand estimation models from the perspective of an airport operator is not sufficient. Therefore this study is considered as the initial step for an airport operator in its efforts to attract airlines and market new air routes to enhance network connectivity of its airport.

Keywords: Estimation, Demand, Opening a New Route, Airport Operator, Enhance Network Connectivity.

\footnotetext{
${ }^{1}$ Senior Manager, Corporate Innovation Team Incheon International Airport Corporation, Incheon, 22382 Korea (+82-32-741-5785, nangli8354@naver.com)

2 Dean, Asia Pacific School of Logistics, Inha University, Incheon, 22212 Korea

${ }^{3}$ Director, Corporate Strategy \& Planning Team, Incheon International Airport Corporation, Incheon, 22382 Korea

${ }^{4}$ Vice President, Passenger Service Division, Incheon International Airport Corporation, Incheon, 22382 Korea
} 


\section{INTRODUCTION}

Regional hub airports can create enormous economic value by attracting air traffic demand into the hub airport on the basis of stronger network competitiveness than adjacent airports. Therefore ultimate competitiveness of an airport can be evaluated by network connectivity, and the network connectivity is a key success factor for an airport to achieve a hub airport position in a region.

Generally, network connectivity of an airport is composed of the number of non-stop destinations to/from the airport and the frequency of flights and wave structure of an airport.

Thus, for an airport operator, it is an important task to attract airlines to open new flight routes and or to increase flight frequencies in existing flight routes, which would directly contribute to enhance network connectivity of an airport. Demand estimation is important, as predicting the potential demand is definitely a basic step to determine the feasibility of opening a new route or increase frequencies. However, because there had been a strong recognition that opening new routes and increasing frequency of flights were mainly decision-making area of the airline for a long time, it might be questioned whether demand estimation could be the working area of an airport operator. Especially how competent an airport operator can be in producing accurate estimation results was very doubtful. In fact, due to the lack of the academic studies on methodologies for estimating demand from opening a new route or increasing flight frequency, it has been widely accepted that there were some issues including the asymmetry of information between the airport operators and the airlines with respect to developing new air-routes.

As aforementioned, however, because opening new routes and increasing flight frequency in existing routes are very important to an airport operator, the challenge to develop a scientific methodology for demand estimation can give rise to great insights for most airport operators. Moreover this challenge can also lead to the expansion of information sharing among players of a market, and this sharing can definitely make a contribution to decrease monopolistic profit that can be easily generated when information is exclusive to a specific player in the aviation industry.

In this study, the methodology to estimate potential demand for a new flight route is introduced. The case of increasing frequency of flights in existing routes can be discussed in a further study. Section 2 represents the insights of the previous studies and Section 3 examines factors to establish a significant estimation model. Section 4 suggests a statistical model to estimate demand from a new flight route. Finally in Section 5, evaluation and possible application areas of this study are discussed. 


\section{REVIEW OF RELATED LITERATURE}

Most researches on demand estimation in the aviation industry have focused on the area of total demand of an airport or a country, which generally apply time-series approaches focusing on recent trend. Abdelghany et al. (2010) presented a time-series modeling approach to forecast total demand of an airport in short-term. Interestingly, their model used various external factors, such as seasonality, fuel price, airline strategies, incidents and financial conditions, giving great implications to establish explanatory variables in this study.

On the other hand, there have been numerous studies on the comprehensive competitiveness of airport network in terms of connectivity. Park et al (2006) proposed a 'Hub index' to evaluate network connectivity. Their index is composed of time connectivity, space connectivity and relative strength. Lee et al (2014) suggested 'Continuous Connectivity Index' which supplemented 'Hub index' by incorporating airline flight schedules. These studies are helpful to understand a general concept of airport connectivity.

The most difficult task in this study is to identify and construct explanation variables. Review of previous studies show that a wide range of variables being considered. For example, Wilken et al (2006) considered airport network density, catchment area of airport, existing traffic volume, airline services and prices in the case of German air passengers choosing transit airports. Grosche et al (2007) suggested distance, population and catchment area as critical variables.

Koo et al (2013) considered capacity in terms of number of available seats at an airport as an explanatory variable reflecting the supply side. Their study is different from other studies in that it explicitly considered a supply aspect in determining possible air demands by analyzing the relationship between available flight seats and the number of passengers in the tourism markets of Japan, Australia and China. In short term, available seats are generally static because of schedule commitments, but, because of elastic passenger demand corresponding to economic conditions, available seats can take critical role as an explanatory variable in a supply aspect so as to find the market equilibrium.

Nicolau (2011) showed that there was higher level of risk aversion and diminishing sensitivity in a demand aspect and that air passengers tend to react more strongly to price increase than price decrease. Thus, price can help enhance the consistency of the demand model as an explanatory variable. Malighetti et al. (2010) also suggested a similar finding that the increasing complexity and dynamism of the air transport industry will enhance the role of pricing. 
In short, previous studies on demand estimation in the aviation industry have applied some common variables, such as population, distance, price, capacity (available seats, frequency). These variables were also considered in estimating demand in this study.

\section{POTENTIAL DEMANDS FOR A NEW ROUTE}

\subsection{Types of Potential Demand}

Potential demand for a new air route was classified into following four types in this study. These types can have a significant meaning to an airport operator, because some of them are the stimulated demand and others are the substituted or re-distributed demand. This difference can affect the airport usage policy such as a landing charge and incentives. For example, it may be desirable to offer more incentives to an airline that stimulates more a newly generated demand.

\subsubsection{Local Demand}

The first type of demand is direct "Local demand" converted from traffic previously connecting through a hub airport (Figure 1). When there is no direct route from AAA (the airport under consideration) to ZZZ (a potential new destination), passengers travelling between AAA to ZZZ have to connect through another airport. Under this circumstance, a new direct flight between AAA and ZZZ will attract and convert some of these "connecting" traffic into direct "Local Demand".

How many "Local demand" will be converted depends on variables, such as characteristics of the destination city, origin/destination airports, etc. These variables are essential factors to establish an estimation methodology, and are discussed in Section 3.2.

In fact, the first type of demand is indiscriminate from existing demand from the perspective of an airport operator, because these passengers already use the airport. However, this kind of demand from a new air route can increase the economic value of the airport, because "Local demand" generally create more economic value than "transit demand".

On the other hand, a new air route can stimulate traveling demand, attracting new passengers to take new direct route to ZZZ. This additional demand is a definitely the newly generated demand. However this study will not consider such stimulated demand, because the amount of this demand can be too small, considering the complexity of estimating such stimulated demand. 
Fig.1. Local demand for a new route

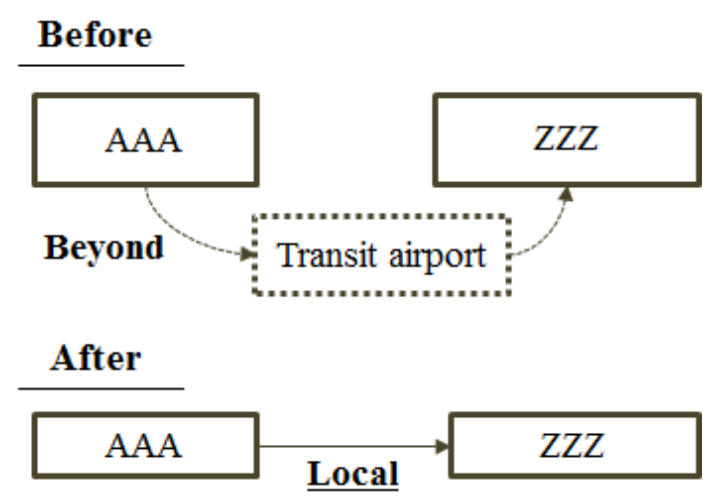

\subsubsection{Beyond Demand}

The second type of demand is "Beyond demand" re-distributed from existing "Beyond demand". (refer to Fig.2.) If there is a new route from AAA to ZZZ, some passengers will select ZZZ as a new transit place to go to their destinations. This type of demand is the re-distributed demand, creating no changes in the number of passengers or economic value from the perspective of AAA.

How many "Beyond demand" using ZZZ as a transit place will be re-distributed is closely related with the detour ratio of 'AAA-ZZZ-final destinations' and frequencies both 'AAA-ZZZ' and 'ZZZ-final destinations'.

Fig.2. Beyond demand for a new route
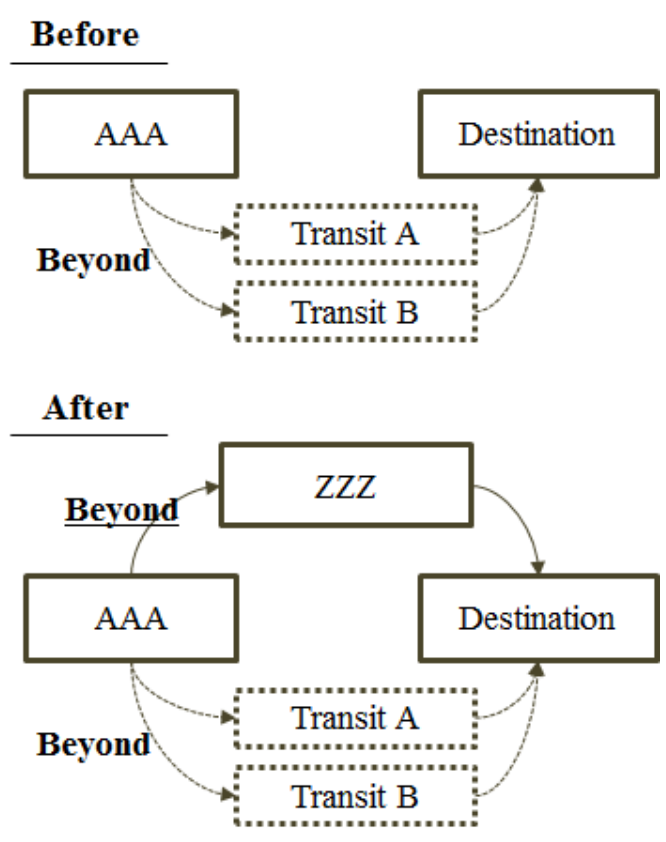


\subsubsection{Behind Demand \#1}

The third type of demand is "Behind demand" which was originally "Behind demand"of competing airports. (refer to Fig.3.) When a new route is open between AAA and ZZZ, some of "Behind demand" of competing airports can be moved into "Behind demand" of AAA. This type of demand seems the most important to $A A A$, because this type is the newly generated demand from the perspective of $A A A$, which means the generated economic value.

How many passengers will use AAA as a new transit place to go to $Z Z Z$ is closely related with the attractiveness of $\mathrm{AAA}$ as a transit place. Thus relative competitiveness AAA compared with competitors, such as 'Transit $A^{\prime}$, and detour ratio of 'origins-AAA-ZZZ' should be considered as variables to establish an estimation methodology.

Fig.3. Behind demand \#1 for a new route

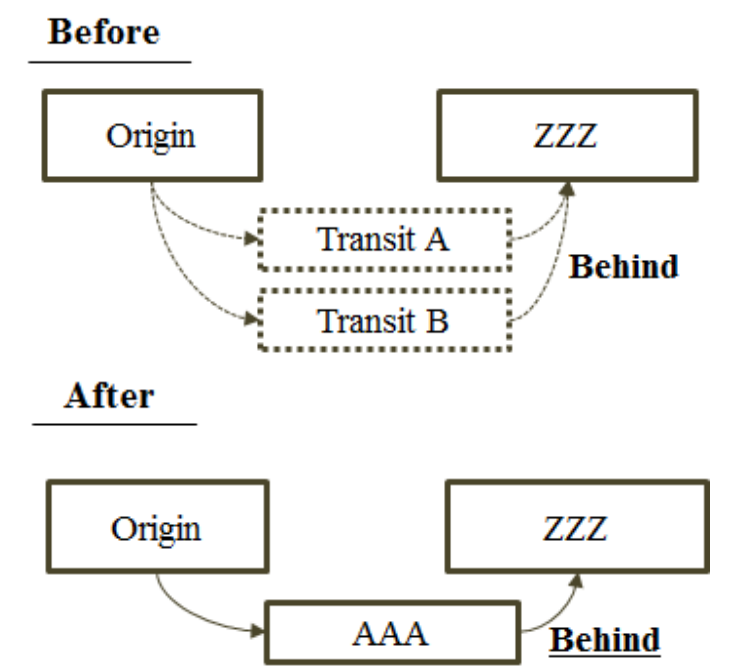

\subsubsection{Behind Demand \#2}

The fourth type of demand is "Behind demand", which was originally "Local demand" of competing airports. (refer to Fig.4.) When a new route is open between AAA and ZZZ, some of "Local demand" of competing airports can be moved into "Behind demand" of AAA. However there is low possibility that the total amount of this kind of demand will be significant, because "Local demand" of competing airports is a passenger who has already made a decision to take a direct flight in spite of numerous options to take a transit flight. Thus it does not seem reasonable to assume that the passenger can change his/her decision, just because there emerges one more option to take a transit flight. 
Fig.4. Behind demand \#2 for a new route
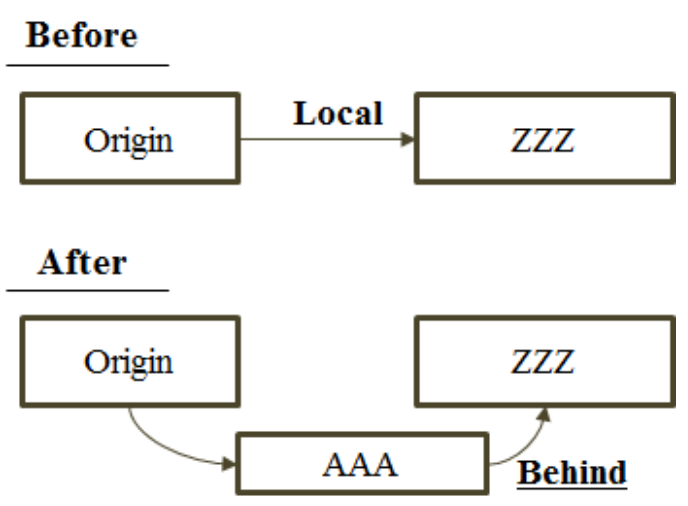

\subsubsection{Bridge Demand}

The fifth type of demand is "Bridge demand". When a new route is open between AAA and ZZZ, AAA can be used as a new bridge point and then this will consist of "Bridge demand". (refer to Fig.5.)

In fact, this fifth type of demand is also the newly generated demand from the perspective of both an airport operator and an airline. However, it can be reasonable selection not to deal with this type of demand, considering that "Bridge demand" originally is not significant type of demand. Therefore this study does not include this type of demand.

Fig.5. Bridge demand for a new route

Before
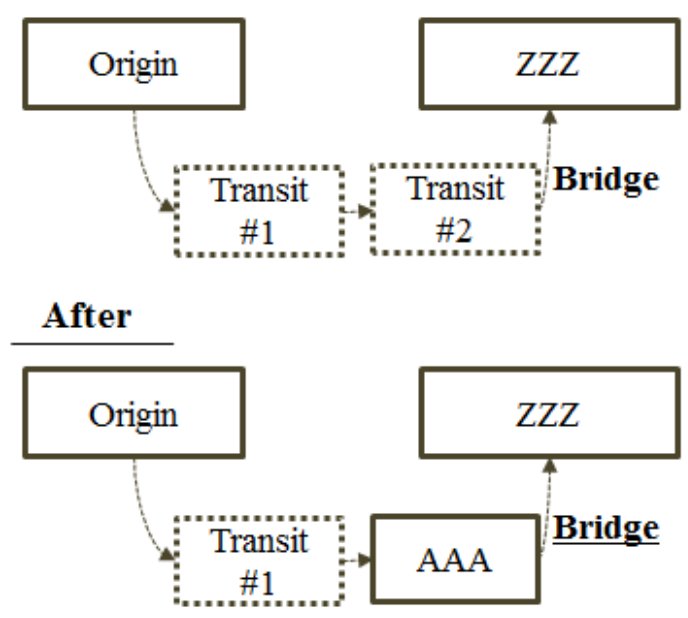


\subsection{Factors to Estimate Demand for a New Route}

There can be a lot of factors to establish an estimation methodology for a new air route, as shown by Section 2. Therefore this study concentrates on finding out 'appropriate' factors. The meaning of 'appropriate' requires that it be i) statistically significant, ii) available to get historical data and iii) easy to process the estimation procedure. This Section examines 'appropriate factors' as variables to estimate demand of each type.

\subsubsection{Local Demand}

Even if there is a direct flight between $A A A$ and $Z Z Z$, some passengers continue to take transit fights, mainly because of price difference between a direct flight and a transit flight. Thus it is unreasonable assuming that all the "Beyond demand"(AAA-transit airport-ZZZ) will be moved into "Local demand"(AAA-ZZZ). Therefore it is necessary to find out which factors will affect "Beyond demand" to move into "Local demand". (refer to Fig.6.) First of all, distance should be considered, because the shorter distance between $A A A$ and $Z Z Z$ means the more passengers taking direct flights. For example, if it takes 3-hour stand-by time for a transit flight to go only 2-hour flight distance, almost all passengers will select direct flights. Therefore the distance from AAA to ZZZ must be an important factor as an explanatory variable.

\section{Fig.6. Structure of Local demand for a new route}

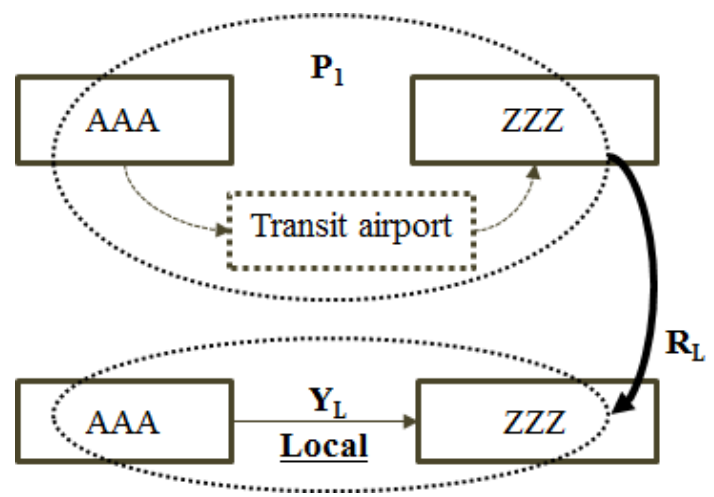

The relative capacity is also an important factor. If there are the more seats provided by direct flights, this can naturally lead to the more direct passengers, not only because of more capacities, but also because of lower price as the result of more capacities. In this regard, relative capacity compared with competing airports can take a role as a proxy index of price, which is usually hard to attain accurate historical data.

Based on this, "Local demand", which is converted from "Beyond demand", can be represented by a below equation.

(Local demand $=$ Potential demand $\times$ Convert rate) 
Potential demand means existing "Beyond demand" between AAA and ZZZ, and Convert rate can be measured from multiple linear regression function that uses distance and relative capacity as independent variables. In this study, the total number of seats provided in AAA airport compared with competing airports is used as relative capacity. The idea of continent (Europe, Asia, North America, South America, Africa, Oceania) is applied to define 'competing airports'. This means that competing airports of AAA are the airports that are located in the same continent as AAA. In short, the equation to estimate converted 'Local Demand' is shown as following equation (1).

$Y_{L}=P_{1} \times R_{L}=P_{1} \times\left(a_{1} \times X_{1}+a_{2} \times X_{2}+\varepsilon\right)$

Where

$Y_{L}:$ Local demand

$P_{1}:$ Potential demand

$R_{L}:$ Convert rate

$X_{1}$ : Distance, $X_{2}$ : Relative capacity

Hypotheses to verify are as below.

$H_{0}: a=0, H_{1}: a \neq 0(a)$

266 historical data of recent 3 years' operation data of Incheon International Airport(ICN) are used to verify whether $a_{1}$ and $a_{2}$ (coefficients) have statistical significance or not. The examples of these data are represented by Table 1 . It is necessary to check whether there is multi-collinearity between 2 independent variables $\left(X_{1}, X_{2}\right)$ to use linear regression model and as shown by Table 2 , there is no multi-collinearity. In addition, there are strong linear relationships between independent variables. (refer to Fig.7.)

Table 1 Historical Data Example - Local Demand

\begin{tabular}{lllc}
\hline $\begin{array}{l}\text { Airport } \\
*\end{array}$ & $\begin{array}{l}\text { Convert } \\
\text { rate** }\end{array}$ & $\begin{array}{l}\text { Distance*** } \\
\text { (miles) }\end{array}$ & $\begin{array}{l}\text { Relative } \\
\text { capacity**** }\end{array}$ \\
\hline HKG & $93 \%$ & 1,270 & 3 \\
\hline BKK & $87 \%$ & 2,281 & 4 \\
\hline LAX & $82 \%$ & 5,987 & 5 \\
\hline
\end{tabular}

* Top 100 direct destinations from ICN in recent 3 years ** Local[ICN-ZZZ] / (Local + Beyond[ICN-ZZZ])

*** Great-circle distance between ICN and destinations ****Relative capacity

\footnotetext{
1 ICN's capacity less than $50 \%$ of adjacent airports

2 ICN's capacity less than $85 \%$ of adjacent airports
} 
ICN's capacity between $85 \%$ and $115 \%$ of adjacent airports

4 ICN's capacity more than $115 \%$ of adjacent airports

ICN's capacity more than $150 \%$ of adjacent airports

Table 2 Correlation Coefficient - Local Demand

\begin{tabular}{l|l}
\hline Pearson's coefficient & Relative capacity \\
\hline Distance & -.399 \\
\hline
\end{tabular}

In Section 4, the multiple regression analysis to fit the statistically significant model between the alternative hypothesis and the null hypothesis is carried out, and significant figures of coefficients, including $a_{1}$ and $a_{2}$, are obtained as a result.

Fig.7. Scatter Plot - Local Demand
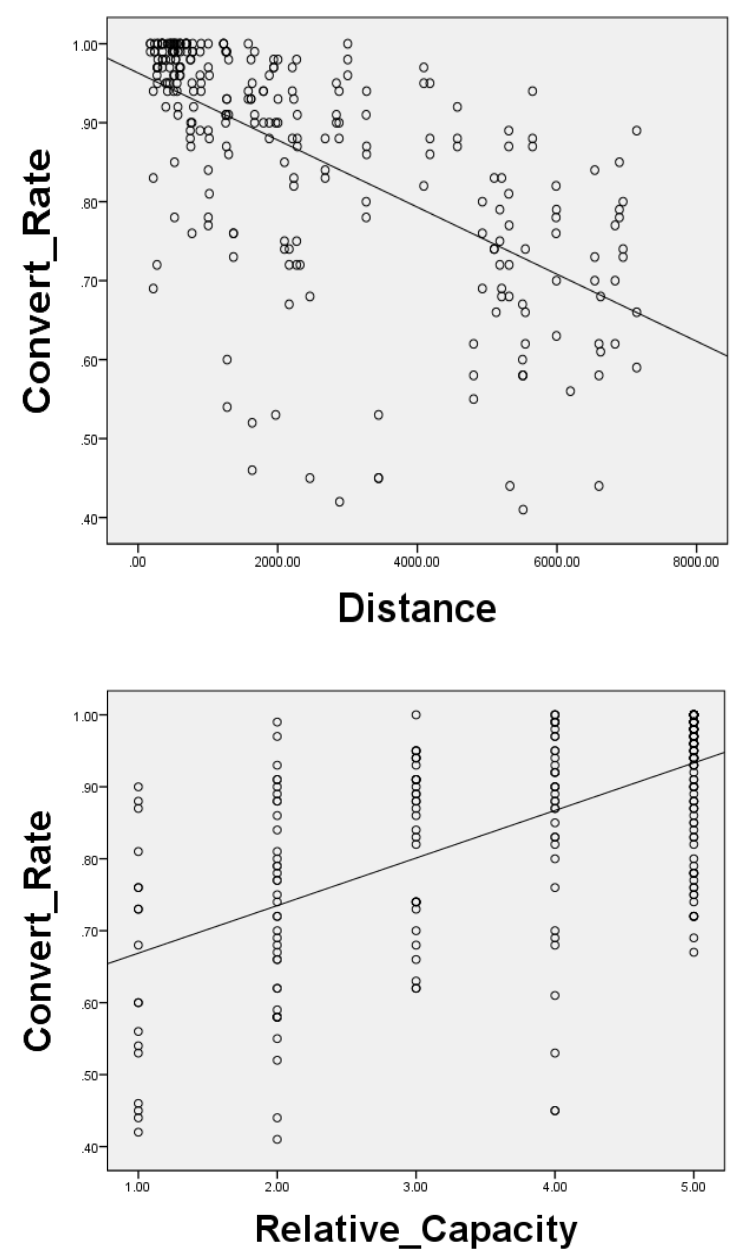


\subsubsection{Beyond Demand}

The attractiveness of $Z Z Z$ as a transit place is closely related with the location itself and network competitiveness of $Z Z Z$, such as flight frequencies between $Z Z Z$ and final destinations. (refer to Fig.8.) Therefore it is necessary to find out which factors will motivate the passengers using other airports to change their transit airports into ZZZ.

Fig.8. Structure of Beyond demand for a new route

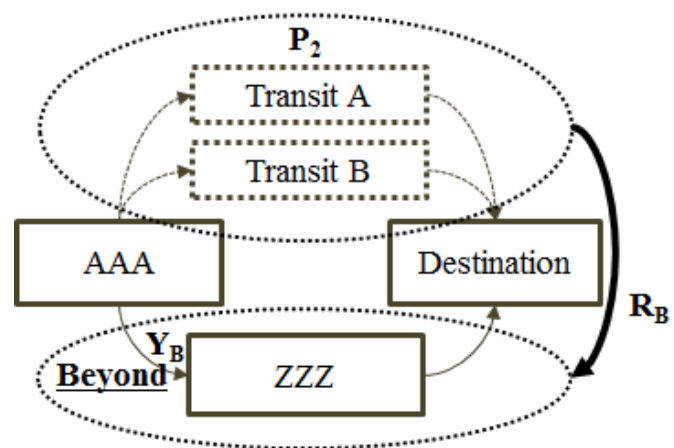

Based on this, "Beyond demand", which uses ZZZ as a new transit place, can be represented by a below equation.

(Beyond demand $=$

Potential demand $\times$ Redistribution rate)

Potential demand means existing "Beyond demand" between AAA and final destinations. Distribution rate is closely related with attractiveness of ZZZ as a transit place to go to such destinations. In this study, in order to assess attractiveness of ZZZ regarding final destinations, detour ratio of 'AAA-ZZZ-final destinations' are used. Detour ratio definitely is a good index of attractiveness as a transit place, because smaller detour ratio generally means the more efficiency, which can affect passengers to change their transit airports. Detour ratio 'AAA-ZZZ-final destination i' can be shown by following formula (2).

$$
\mathrm{D}_{\mathrm{i}}=\left|\begin{array}{l}
\text { Distance of } A A A-Z Z Z+\text { Distance } \\
\text { of } Z Z Z \text {-Destination i }
\end{array}\right|
$$

Where

Distance : Great-circle distance

In short, the estimation equation of this type of demand is as following equation (3) 
$Y_{B}=P_{2} \times R_{B}=P_{1} \times\left(\beta / a_{3} \times D_{i}\right)(3)$

Where

$Y_{B}:$ Behind demand

$P_{2}:$ Potential demand

$R_{B}:$ Redistribution rate

$D_{i}$ : Detour ratio via $Z Z Z$ from $A A A$ to destination $i$.

$H_{0}: a=0, H_{1}: a \neq 0(b)$

109 historical data of recent 3 years' operation results of ICN are used to verify whether this model has statistical significance or not. The examples of these data are represented by Table 3. In ahead of creating a scatter plot to determine the presence of linear relationship between two variables, log transition is committed as a following formula (4), because log transition is more helpful to get an appropriate equation.

$\ln \left(R_{B}\right)=-a_{3} \times \ln \left(D_{i}\right)+\ln (\beta)(4)$

Scatter plot shows that there is a negative linear relationship between independent variables. (refer to Fig.9.) The procedure to estimate "Beyond demand" is as below steps.

i) Find potential demand by each destination of 'Beyond demand' of AAA .

ii) Find distribution rate by each destination as a detour ratio of 'AAA-ZZZ-each destination'

iii) $\sum_{i=1}^{n}($ Potential Demand of Destination $) \times($ Detour Ratio of Destinationi $)$

Table 3 Historical Data Example - Beyond Demand

\begin{tabular}{cccc}
\hline $\begin{array}{c}\text { Destination } \\
*\end{array}$ & $\begin{array}{c}\text { Transit } \\
\text { airport** }\end{array}$ & $\begin{array}{c}\text { Occupancy } \\
\text { rate of the } \\
\text { transit airport } \\
* * *\end{array}$ & $\begin{array}{c}\text { Detour } \\
\text { ratio } \\
* * * *\end{array}$ \\
\hline LHR & AMS & $8.9 \%$ & $101 \%$ \\
\hline LHR & FRA & $5.7 \%$ & $103 \%$ \\
\hline JFK & SFO & $20.5 \%$ & $118 \%$ \\
JFK & HNL & $7.0 \%$ & $127 \%$ \\
\hline
\end{tabular}

* Destination cities from ICN

** Transit airport to the destination from ICN

*** The occupancy rate of using the transit airport among total transit demands

**** Detour ratio from ICN to destination when using transit flight 
In Section 4, the multiple regression analysis to fit the statistically significant model between the alternative hypothesis and the null hypothesis is carried out, and significant figures of coefficients, including $a_{3}$ and $\beta$, are obtained as a result.

\section{Fig.9. Scatter Plot - Beyond Demand}

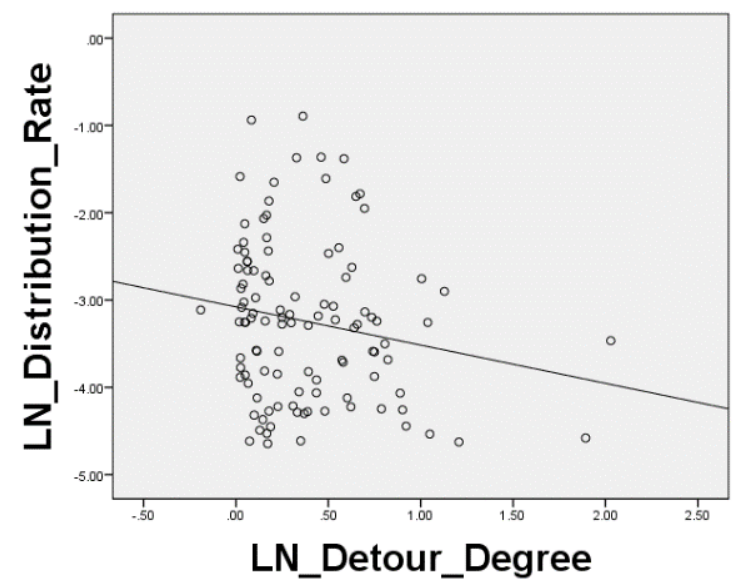

\subsubsection{Behind Demand \#1}

This type of demand is newly generated because it was originally demand of other airports. (refer to Fig.10.)

This type of demand can also represented by a below equation.

(Behind demand $=$

Potential demand $\times$ Transfer rate)

Potential demand means existing "Behind demand" of ZZZ of using other airports as transit places.

Fig.10. Structure of Behind demand \#1 for a new route

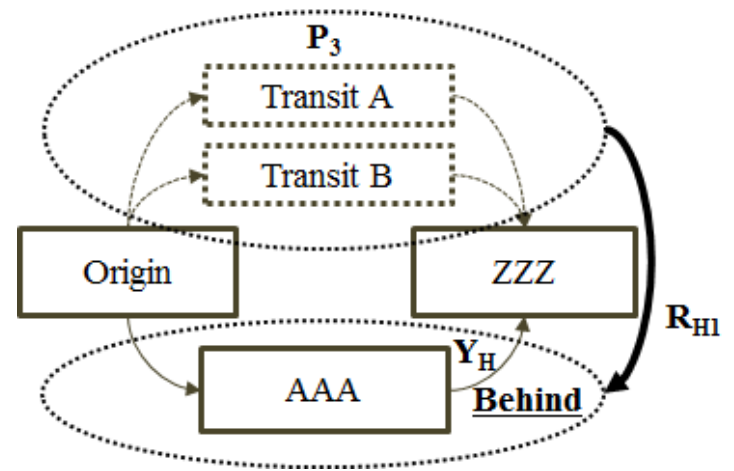

In ahead of making an estimation, it seems reasonable to narrow range of potential demand into demand that has a possibility to be moved into "Behind demand" of AAA. This study adopts the range of maximum detour ratio 3 , because, if the ratio is more than 3 , there will be little possibility 
for passengers to select the airport as a transit place. Detour ratio 3 is similarly adopted in previous studies including Park et al.(2006) and Lee et al.(2014).

This demand is closely related with the attractiveness of AAA as a new transit place, because it is a kind of competition to take over transit passengers. To assess how many passengers will select AAA as a new transit airport, this study uses two dimensions of approach. The first dimension is the strength of AAA itself as a transit place to go to ZZZ. It can be measured by the detour ratio from 'origins-AAA-ZZZ', the same as Section 3.2.2. The other dimension is a relative perspective. In this regard, related capacity competitiveness is an essential factor to take over existing transit demand of other airports. Moreover, as represented in Section 3.2.1, a capacity variable can additionally be used as a proxy index of price. The estimation equation of the third type of demand is as following equation (5)

$Y_{H}=P_{3} \times R_{H 1}=P_{3} \times\left(a_{4} \times X_{4}+a_{5} \times X_{5}+\varepsilon\right)$

Where

$Y_{H}:$ Behind demand

$P_{3}$ : Potential demand

$R_{H 1}:$ Transfer rate

$X_{4}$ : Detour ratio, $X_{5}$ : Relative capacity

Hypotheses to verify are as below.

$H_{0}: a=0, H_{1}: a \neq 0(c)$

72 historical data of recent 3 years' operation results of ICN are used to verify whether this model has statistical significance or not. The examples of these data are represented by Table 4. As shown by table 5 , it seems that there is no multi- collinearity among independent variables. In addition, it seems that there are strong linear relationships between independent variables. (refer to Fig.11.)

Table 4 Historical Data Example - Behind Demand \#1

\begin{tabular}{ccccc}
\hline $\begin{array}{c}\text { Destination } \\
*\end{array}$ & Origin** & $\begin{array}{c}\text { Transfer } \\
\text { Rate****}\end{array}$ & $\begin{array}{c}\text { Detour } \\
\text { ratio } \\
* * * *\end{array}$ & $\begin{array}{c}\text { Relative } \\
\text { Capacity } \\
* * * * *\end{array}$ \\
\hline BKK & JFK & $20.5 \%$ & 1.589 & 6 \\
\hline HKG & LAX & $20.4 \%$ & 2.387 & 6 \\
\hline HNL & PEK & $45.2 \%$ & 1.216 & 7 \\
\hline SGN & YYZ & $13.0 \%$ & 1.412 & 3 \\
\hline
\end{tabular}

* Destination cities when transferring at ICN

** Origin cities when transferring at ICN

*** The occupancy rate of using ICN as a transit airport

among existing transit demands within detour ratio 3 via ICN

**** Detour ratio via ICN from a origin to a destination

***** Relative capacity: Sum of Relative capacity of both

Origin-ICN and ICN-destination 


\section{Table 5 Correlation Coefficient - Behind Demand \#1}

\begin{tabular}{l|l}
\hline Pearson's coefficient & Relative capacity \\
\hline Detour ratio & -0.0899 \\
\hline
\end{tabular}

In Section 4, the multiple regression analysis to fit the statistically significant model between the alternative hypothesis and the null hypothesis is carried out, and significant figures of coefficients, including $a_{4}$ and $a_{5}$, are obtained as a result.

Fig.11. Scatter Plot-Behind Demand \# 1
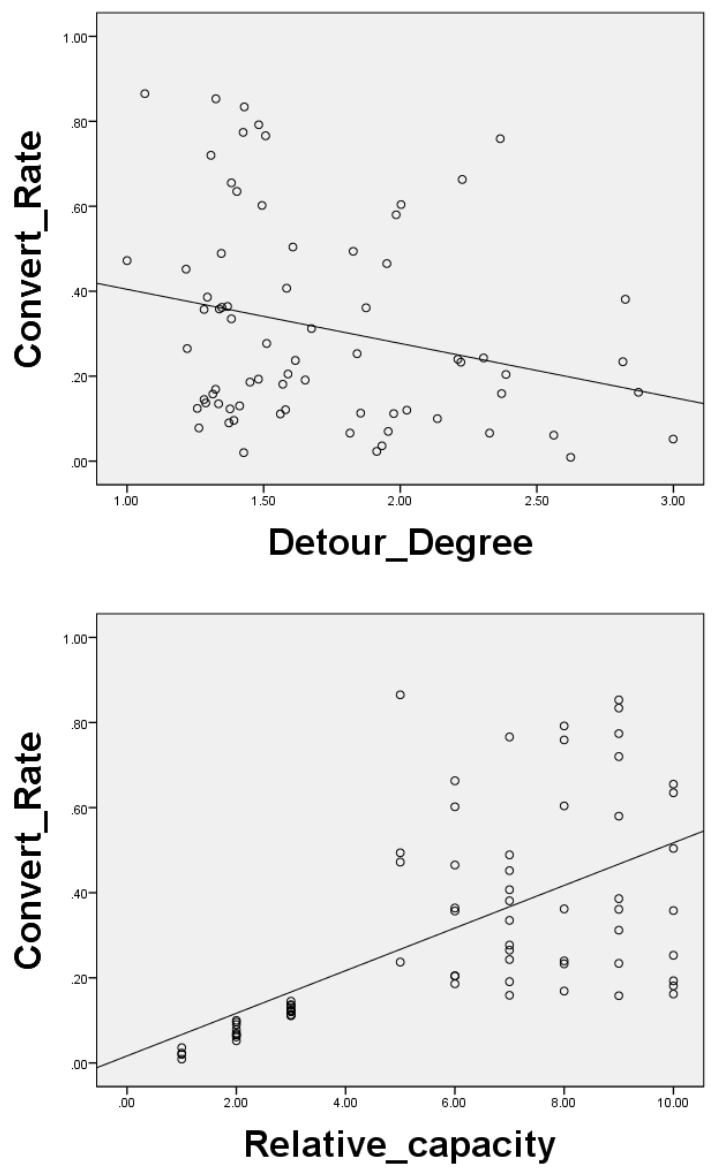

\subsubsection{Behind Demand \#2}

When there is a new route from AAA to $Z Z Z$, there can also be "Behind demand", which is moved from "Local demand" of competing airports. (refer to Fig.12.) As the same as the case of 'Behind demand \#1 estimation', it is reasonable to assume that only the demand within detour ratio 3 via AAA has a possibility to be moved. The estimation equation of the fourth type of demand is as following equation (6)

$Y_{H}=P_{4} \times R_{H 2}$

Where $Y_{H}$ : Behind demand 
$P_{4}:$ Potential demand

$R_{H 2}:$ Transfer rate

As represented in Section 3.1.4, there is low possibility that the total amount of this kind of demand will be significant. Therefore this study used empirical figures to measure transfer rate $\left(R_{\mathrm{H} 2}\right)$, instead of establishing statistical model to assess it. For example, the average of past transfer rates from empirical cases of opening new routes in AAA airport can be used.

Fig.12. Structure of Behind demand \#2 for a new route

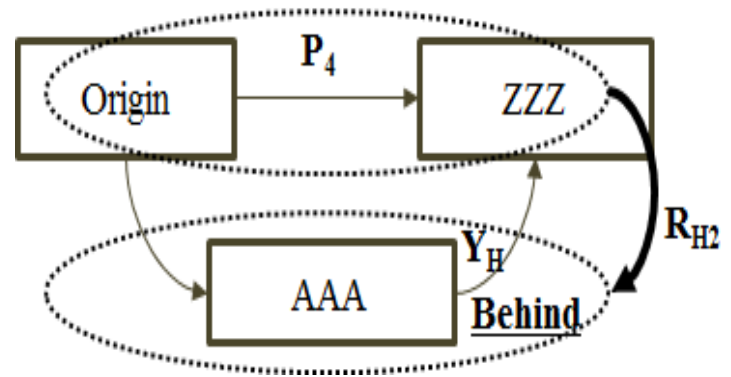

\section{SUGGESTION OF ESTIMATION METHOD}

In previous Sections, the types of potential demand for a new air route and appropriate explanatory variables are established. In this Section, the variables are verified by a statistical tool to judge whether they are statistically significant or not as independent variables.

\subsection{Statistical Review}

\subsubsection{Local Demand}

The equation that needs statistical verification is as following equation (1).

$Y_{L}=P_{1} \times R_{L}=P_{1} \times\left(a_{1} \times X_{1}+a_{2} \times X_{2}+\varepsilon\right)$

Where

$Y_{L}:$ Local demand

$P_{1}:$ Potential demand

$R_{L}:$ Convert rate

$X_{1}$ : Distance, $X_{2}:$ Relative capacity

Using 266 historical data of ICN, multiple regression analysis is conducted and the result is proved to be statistically significant. (refer to Table.6.) Therefore, $H_{0}$ hypothesis $\left(H_{0}: a_{1}\right.$ and $\left.a_{2}=0\right)$ is rejected and $H_{1}$ hypothesis $\left(H_{1}: a_{1}\right.$ and $\left.a_{2} \neq 0\right)$ is accepted. As a result, significant figures of $a_{1}$ and $a_{2}$ of ICN are obtained. 
Table 6 Statistical Review - Local Demand

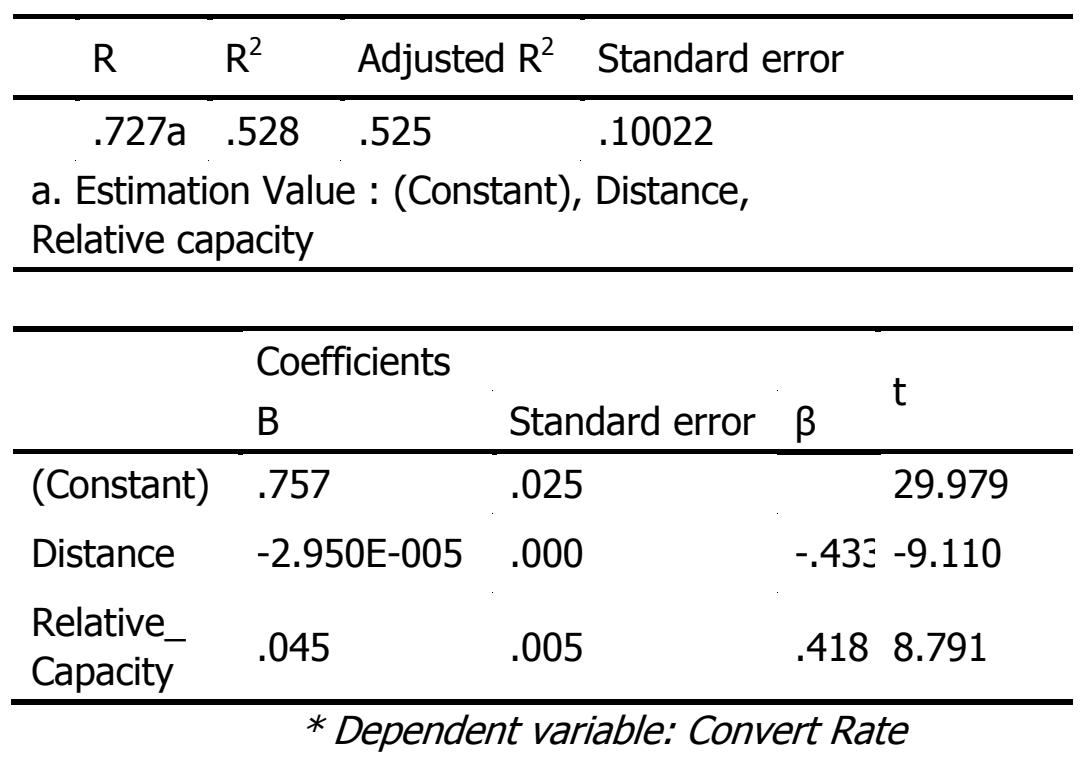

\subsubsection{Beyond Demand}

The equation that needs statistical verification is as following equation (4).

$\ln \left(R_{B}\right)=-a_{3} \times \ln \left(D_{i}\right)+\ln (\beta)(4)$

Where

$R_{B}:$ Redistribution rate

$D_{i}$ : Detour ratio via $Z Z Z$ from $A A A$ to destination $i$

Using 109 historical data of ICN, simple regression analysis is conducted and the result is proved to be statistically significant. (refer to Table.7.) Therefore, $H_{0}$ hypothesis $\left(H_{0}: a_{3}=0\right)$ is rejected and $H_{1}$ hypothesis $\left(H_{1}: a_{3} \neq 0\right)$ is accepted. As a result, significant figures of $a_{3}$ and $\beta$ of ICN are obtained. Removing log transition is as below equation (3-1)

$Y_{B}=P_{2} \times R_{B}=P_{2} \times\left(1 / a_{3} \times D_{i}\right)(3-1)$

Where

$Y_{B}:$ Behind demand

$P_{2}:$ Potential demand

\subsubsection{Behind Demand \#1}

The equation that needs statistical verification is as following equation (5)

$Y_{H}=P_{3} \times R_{H 1}=P_{3} \times\left(a_{4} \times X_{4}+a_{5} \times X_{5}+\varepsilon\right)$

Where 
$Y_{H}:$ Behind demand

$P_{3}:$ Potential demand

$R_{H 1}:$ Transfer rate

$X_{4}$ : Detour ratio, $X_{5}$ : Relative capacity

Using 72 historical data of ICN, multiple regression analysis is conducted and the result is proved to be statistically significant. (refer to Table.8.) Therefore, $H_{0}$ hypothesis $\left(H_{0}: a_{4}\right.$ and $a_{5}=0$ ) is rejected and $H_{1}$ hypothesis $\left(H_{1}: a_{4}\right.$ and $\left.a_{5} \neq 0\right)$ is accepted. As a result, significant figures of $a_{4}$ and $a_{5}$ of ICN are obtained.

Table 7 Statistical Review - Beyond Demand

\begin{tabular}{|c|c|c|c|c|}
\hline $\mathrm{R}$ & $\mathrm{R}^{2}$ & usted $\mathrm{R}^{2}$ & Standard & error \\
\hline $.727 a$ & .528 & & 2.32496 & \\
\hline \multicolumn{5}{|c|}{ a. Estimation Value : LN(Detour ratio) } \\
\hline & \multicolumn{3}{|c|}{ Coefficients } & \multirow[b]{2}{*}{$\mathrm{t}$} \\
\hline & B & $\begin{array}{l}\text { Standard } \\
\text { error }\end{array}$ & B & \\
\hline $\begin{array}{l}\text { LN(Detour } \\
\text { Ratio) }\end{array}$ & -4.584 & .417 & -.727 & -10.9 \\
\hline
\end{tabular}

Table 8 Statistical Review - Behind Demand \#1

\begin{tabular}{|c|c|c|c|c|}
\hline $\mathrm{R}$ & $\mathrm{R}^{2}$ & \multicolumn{2}{|c|}{ Adjusted $\mathrm{R}^{2}$ Standard error } & \\
\hline $.756 a$ & .571 & \multicolumn{2}{|c|}{.15992} & \\
\hline \multicolumn{5}{|c|}{$\begin{array}{l}\text { a. Estimation Value : (Constant), Detour Ratio, } \\
\text { Relative capacity }\end{array}$} \\
\hline & \multicolumn{3}{|c|}{ Coefficients } & \multirow[b]{2}{*}{$\mathrm{t}$} \\
\hline & B & $\begin{array}{l}\text { Standard } \\
\text { error }\end{array}$ & $\beta$ & \\
\hline (Constant) & .121 & .085 & & 1.430 \\
\hline Detour Ratio & -0.085 & .040 & -.166 & -2.096 \\
\hline $\begin{array}{l}\text { Relative_ } \\
\text { Capacity }\end{array}$ & .062 & .007 & .718 & 9.045 \\
\hline
\end{tabular}




\subsubsection{Behind Demand \#2}

The transfer rate $\left(R_{\mathrm{H} 2}\right)$ from existing "Local demand" into "Behind demand \#2" of ICN is calculated by the average of historical figures from empirical cases of opening a new air route at ICN. Since Mar, 2001 when ICN started its operation, there have been almost 100 newly open air routes and the average figure of transfer rate from those open routes can be used as $R_{\mathrm{H}_{2}}$ of ICN. If the figure is the same as $\theta$, the estimated "Behind demand \#2" of ICN moved from existing "Local demand"s of ZZZ for a new air route is estimated by below equation (6-1)

$\mathrm{Y}_{\mathrm{H}}=\mathrm{P}_{4} \times \theta$

Where

$Y_{H}:$ Behind demand

$P_{4}:$ Potential demand

$\theta:$ The average of historical transfer rate

\subsection{Suggestion of Estimation Method}

Using the independent variables and coefficients established in previous Sections, this study suggests demand estimation method for a new air route as following equation (7).

Potential demand $=$ Local demand +

Beyond demand + Behind demand

$=P_{1}^{a)} \times\left(a_{1} \times X_{1}^{b)}+a_{2} \times X_{2}^{c)}\right)+P_{2}^{d)} \times e^{(a 3} \times{ }^{\ln (X 3)) e)}+$

$P_{3}{ }^{f)} \times\left(a_{4} \times X_{4}{ }^{g)}+a_{5} \times X_{5}^{(h)}\right)+P_{4}^{i)} \times \theta^{j)}$

Where

a) Existing 'Beyond demand' of $A A A, A A A$ to $Z Z Z$

b) Great-circle distance, $A A A$ to $Z Z Z$

c) Flight seats provided in $A A A, A A A$ to $Z Z Z$

*expressed as a relative index by comparison with competing airports

d) Existing 'Beyond demand' of $A A A$

e) Detour ratio of ' $A A A-Z Z Z$ - existing destinations of $A A A^{\prime}$

f) Existing 'Behind demand' of ZZZ within detour ratio 3 when using $A A A$ as a transit point

g) Detour ratio 'existing origins of $Z Z Z-A A A-Z Z Z$ ' 
h) Sum of relative capacity both existing origins of (Origin to $A A A$ ) and ( $A A A$ to $Z Z Z$ )

*expressed as a relative index by comparison with competing airports

i) Existing 'Local demand' of ZZZ within detour ratio

3 when using $A A A$ as a transit point

j) Average of historical transfer rates from 'Local demand' of new destinations to 'Behind demand' of $A A A$ for historical new air routes at $A A A$

Actually the amount of potential demand from above equation (7) is the figure of one-way direction $(A A A \rightarrow Z Z Z)$. Therefore, to estimate total round-trip amount, it is necessary to multiply the amount from equation (7) by 2, although there can be a slight difference of demand between firstway $(A A A \rightarrow Z Z Z)$ and second-way $(Z Z Z \rightarrow A A A)$.

The newly generated demand from the perspective of AAA is as following equation (7-1). This amount can also be a whole new demand to an airline, only if the airline has no direct route between AAA and ZZZ in other airports.

Newly generated demand (Airport perspective) $=$

$P_{3}{ }^{f)} \times\left(a_{4} \times X_{4}{ }^{g)}+a_{5} \times X_{5}{ }^{h)}\right)+P_{4}{ }^{i)} \times \theta^{j)}$

\section{CONCLUSION AND RECOMMENDATIONS}

To evaluate a potential new air route at an airport, four types of potential demands must be considered. The first one is the direct "Local demand" that are converted from connecting traffic through another airport; the second one is re-distributed "Beyond demand"; the third one is "Transferred Behind demand"; and the fourth one is "Transferred Bridge demand". The estimation of the potential demand is critical in making the decision whether to start a route or not.

In short, this study develops the models for estimating each type of demand for a new air route. The proposed methodology is applied to Incheon International Airport, and the results indicate that explanatory variables, such as distance, relative capacity and detour ratio, are statistically significant.

The suggested estimation methodology can offer important insights. At first, this methodology has good explanatory power to estimate potential demand from a new air route, using linear regression model. Secondly independent variables in this methodology are closely related with each type of potential demand and these variables can be attained through existing tools such as Sabre MIDT, OAG, etc. Moreover, the assumptions used in this study appear to be reasonable and the methodology reflects real market trend. Finally the methodology provides distinction between the 
newly generated demand and the converted or redistributed demand from the perspective of an airport.

Yet, this study definitely has limitations, such that it can take too much time to obtain appropriate data and to conduct estimation procedures. Besides, there are some unclear points, including the definition of 'competing airports' and less sophisticated concept of 'relative capacity'.

However, it is certain that this attempt to estimate potential demand for a new air route from the perspective of an airport is valuable. Also this attempt is definitely important step for an airport operator in its efforts to attract airlines and marketing air routes in order to enhance network connectivity of the airport. 


\section{REFERENCES}

- Abdelghany, A., and Guzhva, V.S. (2010). Time-series modelling approach for airport short-term demand, Journal of Airport Management, Vol 5, No 1, pp.72-87.

- $\quad$ Park, Y.H., Kim, S.Y., and Kim, J.Y. (2006). An analysis for transferring connectivity at Incheon International Airport, J. Korean Soc. Transp., Vol 24, No 6, pp.75-85.

- Lee, S.Y., Yoo, K.E., and Park, Y.H. (2014). A continuous connectivity model for evaluation of hub -and-spoke operations, Transportmetrica A: Transport Science.

- Wilken, D., Berster, P., and Gelhausen, M. (2006). Airport choice in Germany : New empirical evidence of the 2003 German air traveller survey, Journal of Airport Management, Vol 1, No 2, pp.165-179.

- Grosche, T., Rothlauf, F., and Heinzl, A. (2007). Gravity models for airline passenger volume estimation, Journal of Air Transport Management, Vol 13, No 4, pp175-183.

- Koo, T.T.R., Tan, D.T., and Duval, D.T. (2013). Direct air transport and demand interaction : A vector error-correction model approach, Journal of Airport Management, Vol 28, pp.14-19.

- Nicolau, J.L. (2011). Testing prospect theory in airline demand, Journal of Air Transport Management, Vol 17, No 4, pp241-243. 